\title{
Selfie de protesta y construcción social de sentido: Un acercamiento desde la semiótica social*
}

\section{Protest selfie and social construction of meaning: An approach from social semiotics}

\author{
Catalina Büchner** \\ Universidad Austral de Chile, Chile \\ catabuchner@gmail.com
}

\begin{abstract}
Resumen Este artículo plantea un acercamiento teórico desde la semiótica social de Bajtin y Voloshinov a una modalidad textual que ha sido ampliamente difundida a través de Internet, dispositivos digitales portátiles y redes sociales. Esta modalidad es la selfie de protesta. En este trabajo se afirma que los usuarios, a través de estos mensajes políticos multimodales, se manifiestan, protestan, dialogan y ejercen agencia social. Lo anterior es posible gracias a la instrumentalización de los códigos y a la subversión de los usos tradicionales de la fotografía.
\end{abstract}

\begin{abstract}
This article suggests a theoretical approach, from Bajtin and Voloshinov's social semiotic, to a textual format which has been widely used due to the popularization of Internet, mobile digital devices, and social networks. This modality is known as protest selfie. In this work it is affirmed that the users of social networks -through the above mentioned multimodal political messages-demonstrate, protest, dialogue, and execute social agency. This is possible thanks to the instrumentalization of codes, and the subversion of the traditional uses of photography.
\end{abstract}

\section{Palabras clave \\ Selfie de protesta, compartir, interacción, semiótica social \\ Key words \\ Protest selfie, sharing, interaction, social semiotics}

\footnotetext{
* El presente artículo forma parte de los resultados iniciales del proyecto Fondecyt N¹150545 "Redes Sociales y Medios de Comunicación: Modelo de análisis basado en minería de datos para la comprensión del ecosistema informativo chileno en internet y la educomunicación ciudadana en la red".

** Profesora de Comunicación en Lengua Inglesa, estudiante del programa Magíster en Comunicación, Universidad Austral de Chile.
} 


\section{Introducción}

La conjunción de las múltiples crisis económicas y de legitimidad de los sistemas políticos a nivel mundial, y el creciente uso de Internet, las redes sociales y dispositivos digitales móviles (celulares, tablets, cámaras fotográficas digitales) han dado paso a la emergencia y utilización de una modalidad textual digital denominada selfie de protesta. La selfie, aun cuando es ampliamente producida y utilizada, ha sido habitualmente entendida como una expresión de vanidad, hedonismo o narcisismo (Halpern y Valenzuela, 2016; Finol, 2014). Sin embargo, en el presente artículo sostiene que este autorretrato digital puede ser mucho más que eso. Entre otras cosas, la selfie puede ser un vehículo de comunicación; un mensaje complejo; un mensaje personal y también interpersonal; un mensaje multimodal; y un mensaje político (Senft y Baym, 2015).

Se ofrecerá un acercamiento teórico a la selfie de protesta, desde la perspectiva de la semiótica social de Valentin Voloshinov y Mijail Bajtin. Puesto que interesa enfocar los conceptos que explican el contexto de enunciación de dichos mensajes y la producción social de sentido que involucran.

\section{Marco Teórico}

\subsection{Crisis política y nuevos espacios}

A nivel mundial, principalmente dos hechos han visibilizado el estado de 'crisis' en que se encuentran los sistemas políticos conocidos como democracia representativa y el sistema económico capitalista neoliberal: las altas tasas de abstención en los procesos electorales y la emergencia en la escena política de múltiples movimientos sociales (Millaleo y Cárcamo, 2013), que se han manifestado en uno de los espacios públicos tradicionales por excelencia -la calle- y, además, en las redes sociales online. Éstas últimas han venido a instituirse como espacio público virtual o ágora virtual, en el cual el activismo ciudadano y la protesta social que han sido invisibilizados por los medios masivos de comunicación (Sapiezynska, 2014) convergen, se desarrollan y se renuevan.

En palabras de Barkai (2012), las luchas políticas se emplazan y desarrollan en lugares distintos de manera simultánea -online y offline- pero ejercen influencias mutuas, aportando al desarrollo del conflicto como totalidad. La existencia de otro espacio para la manifestación pública complementa a los antiguos, lejos de reemplazarlos, y la ciudadanía 
se configura bifaz, incluyendo una faceta digital. En este sentido, la ciudadanía digital ha sido definida como la habilidad para participar en la sociedad online, mientras que ciudadanos digitales son aquellos que usan Internet de manera regular y efectiva día a día (Mossberger, Tolbert y McNeal, 2008).

Sierra y Gravante (2016) afirman que la relación que los ciudadanos establecen con los medios digitales les permite organizarse a través de prácticas donde la horizontalidad prevalece. Entre los múltiples casos que ilustran lo anterior, se encuentran los casos del movimiento \#YoSoy132 en México y los pingüinos en Chile ${ }^{1}$. Ambos movimientos relevaron “los rasgos de una nueva subjetividad, de una nueva ciudadanía dispuesta al diálogo y al debate, a la deliberación y decisión colectiva, con mayor capacidad de autonomía y empoderamiento" (169-170).

Los nuevos medios digitales se han erguido como espacios de manifestación, diálogo e interacción, "demostrando, [además], su capacidad de gatillar acciones que salen de la virtualidad de las redes y afectan la materialidad de la vida en común" (Fábrega y Paredes, 2013: 204). La red se instala como un espacio y mecanismo más democrático, que permite la formación de una 'nueva politicidad', cuya principal característica es el desarrollo de acciones que, si bien se desarrollan en la cotidianeidad, suceden en lugares distintos a aquellos donde tradicionalmente se desenvuelve la política (PNUD, 2009), actuando de manera complementaria.

Junto a estos nuevos espacios de comunicación y participación ciudadana ha surgido un tipo de dispositivo específico, que los usuarios de las redes sociales utilizan, entre otras cosas, para emitir mensajes políticos o de protesta: la selfie.

\subsection{De lo doméstico a la domesticación de la fotografía: Selfies}

En relación a la fotografía, no solo sus aspectos técnicos han variado y evolucionado a lo largo de su historia. De acuerdo a Acosta (2015), la sucesión de procesos de evolución

1 \#YoSoy132, también conocido como La Primavera Mexicana, fue un movimiento social organizado, inicialmente, por estudiantes universitarios, en plena campaña presidencial el año 2012 en México. Quienes han estudiado este movimiento han señalado que surgió a partir de la confrontación entre un grupo de estudiantes de educación superior y el entonces candidato a la presidencia Enrique Peña Nieto. Para obtener mayor información sobre el movimiento y los análisis que de él se han hecho, ver Galindo y González-Acosta (2013). En el caso de los pingüinos en Chile, el año 2006 comienza un ciclo de movilización estudiantil que puso en cuestión la naturaleza, estructura y funcionamiento del sistema educativo nacional, coherente con el sistema neoliberal. En ese marco, los jóvenes se manifestaron en las calles y se tomaron tanto los establecimientos educacionales como los medios de comunicación. Respecto a este movimiento en particular y a los movimientos juveniles en Chile en general, ver Aguilera (2014) y Cárdenas (2014). 
técnica, que va desde la daguerrotipia hasta la actual utilización de aparatos digitales, ha traído consigo una 'reconfiguración' de los usos posibles de la fotografía y de nuestra forma de relacionarnos tanto con los aparatos con los que se producen, como con las imágenes mismas. En relación a esto último, se ha sostenido que, antes de la emergencia de las imágenes digitales, las fotografías eran entendidas como artefactos que pertenecían al mundo de lo privado, es decir, eran producidas, compartidas y almacenadas en contextos íntimos (Farías, 2015). Lejos de ello, hoy las fotografías digitales son ampliamente distribuidas y compartidas a través de Internet y las redes sociales con diversos fines, alcanzando audiencias extensas y para nada familiares.

Un tipo particular de fotografía digital es aquella denominada selfie, definida por Oxford Dictionaries (2015) como una "[f]otografía que uno mismo se toma, típicamente con un smartphone o webcam y que es compartida en las redes sociales" ${ }^{2}$, como se muestra en la Imagen 1. En cuanto a sus funciones, ya he sostenido que ésta puede configurarse como un mensaje político y es en relación a esta última función que la selfie de protesta cobra particular relevancia, ya que tiene que ver con asuntos políticos actuales como el "(...) autocontrol, [la] gobernanza y [la] protesta"3 (Burns, 2015).

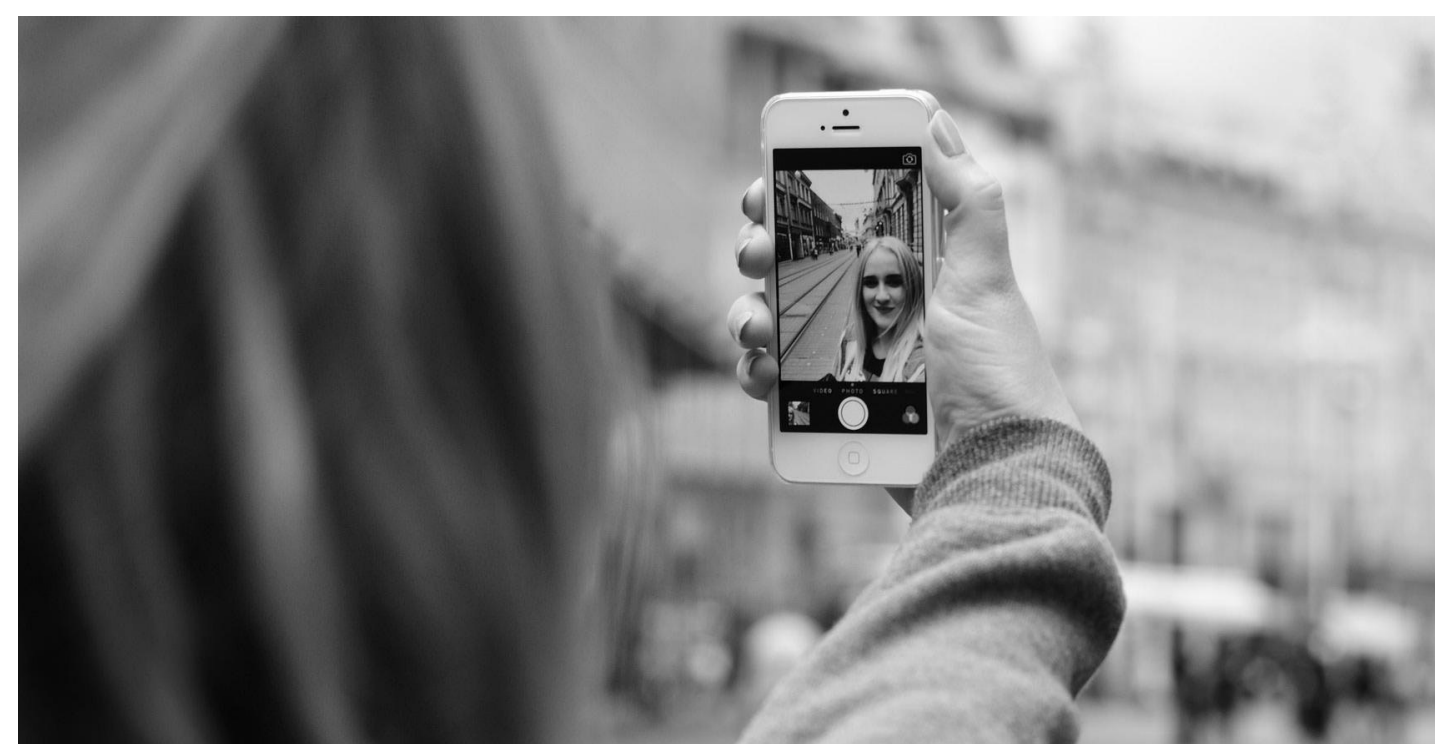

Imagen 1. Persona tomando una selfie. Autofoto con una estatua de los soldados de Napoleón en Bratislava, Eslovaquia. Fuente: www.publicdomainpictures.net

2 "A photograph that one has taken of oneself, typically one taken with a smartphone or webcam and shared via social media". Esta traducción es de la autora del artículo y lo serán todas aquellas que aparezcan en adelante.

3 "(...) including self-monitoring, governance and protest." 
Al referirme a protesta, aludiré al concepto de protesta social, definida por Schuster y Pereyra (2001) como "los acontecimientos visibles de acción pública contenciosa de un colectivo, orientados al sostenimiento de una demanda (en general con referencia directa o indirecta al Estado)". La protesta social comporta un carácter político cuando "problematiza el orden existente, ya que para ser satisfecha se necesita realizar un cambio en ese orden" (Schuster y Pereyra, 2001). En cuanto a la selfie, su relación con la protesta es que, en muchos casos, quienes las publican y comparten interpelan a figuras de autoridad para que actúen cambiando el statu quo de una situación o suceso que ha movilizado a la ciudadanía a manifestarse.

\section{Composición de la selfie de protesta: Cuerpo del emisor autorretratado}

Esta sección se dedica a la descripción de los elementos que constituyen la selfie de protesta. Poniéndo particular énfasis en la presencia del cuerpo del autor del autorretrato y en explicar brevemente cómo dichos elementos operan en conjunto para significar. Además, se explica el rol que cumplen las acciones de publicar y compartir estos mensajes digitales.

Se ha dicho que existe un tipo particular de selfie, el cual he denominado selfie de protesta. Éstas son selfies en las que, además del autor de la fotografía, es posible apreciar un mensaje de protesta, normalmente escrito. Por lo tanto, dichos mensajes son multimodales y presentan distintos niveles y relaciones de significación. Cabe reparar en el significado de multimodalidad, el cual "apunta a la variedad de modos o recursos semióticos utilizados para significar y que confluyen en un mismo evento comunicativo" (Manghi, 2011:4). En el mismo sentido, Kress (2005) afirma que un mensaje es multimodal cuando combina distintos 'modos' o recursos producidos social o culturalmente para significar, conformando un complejo significante. En el caso de la selfie, a simple vista confluyen tanto elementos lingüísticos como no lingüísticos: ítems, léxicos, frases u oraciones y distintos tipos de imágenes.

En cuanto a los primeros, tenemos palabras escritas, pertenecientes a alguna lengua natural como el inglés, en el caso de Imagen 2. Respecto a esto, las lenguas naturales han sido catalogadas por Lotman y Escuela de Tartu (1979) como "sistemas de modelización primarios" (77), ya que a partir de ellas se crean las culturas, actuando como mecanismos estereotipadores. 


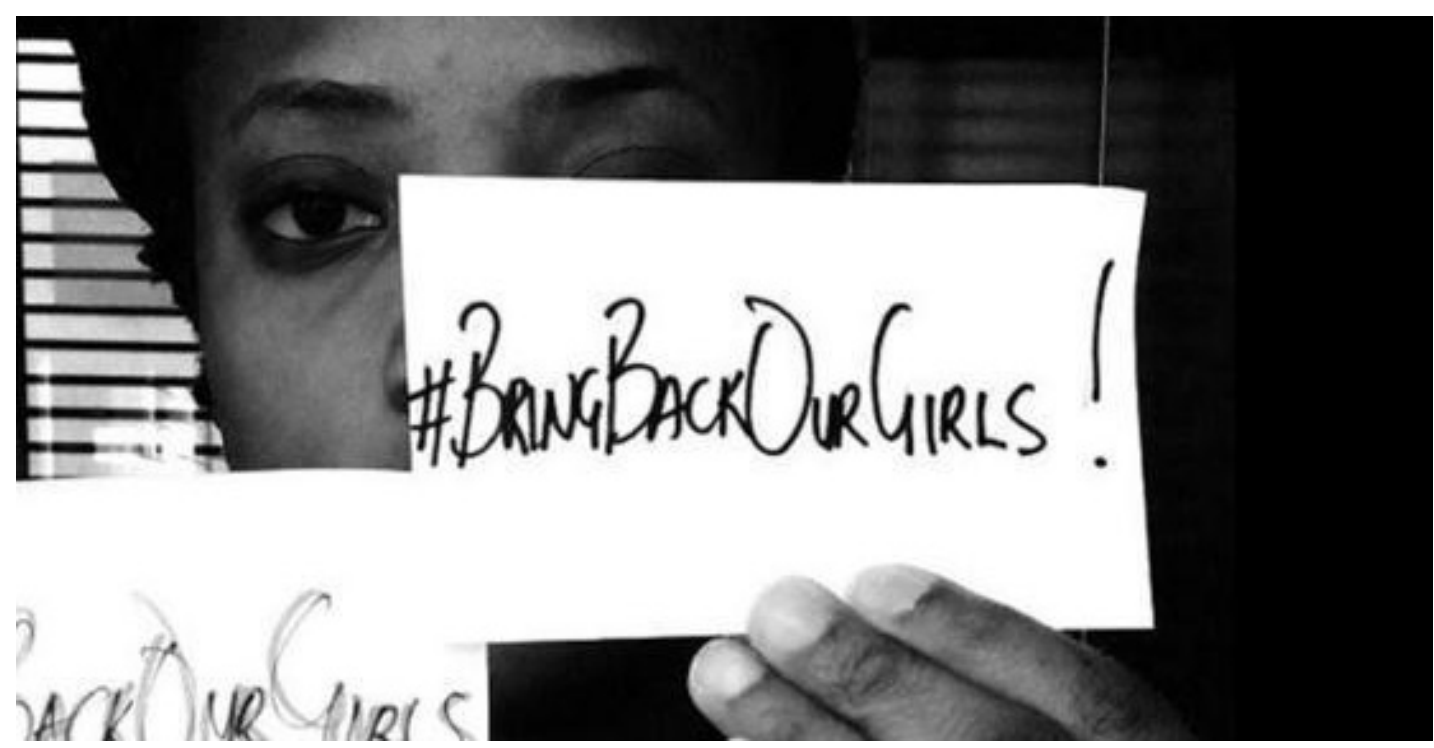

Imagen 2. Selfie de protesta. Fuente:www.brixtonbuzz.com.

Las lenguas naturales modelan o definen los códigos que conforman las culturas en dos sentidos: "proporcionan recursos expresivos que alimentan a lenguajes secundarios a la vez que constituyen un mecanismo que permite su traducción" (Moulian, 2008: 77). Luego, los nuevos entramados semióticos constitutivos de la cultura se denominan "sistemas de modelización secundarios" (Lotman y Escuela de Tartu, 1979), entre los que cuentan sistemas tan complejos como el arte, la religión y la ciencia.

En cuanto a los componentes no lingüísticos de la selfie de protesta, señalaré que el más relevante es el cuerpo del emisor autoretratado. En relación a esto, Vázquez (2003) ha afirmado que la emisión del signo, la proyección de uno mismo - del self- a través de los dispositivos fotográficos se establece a partir de una 'triple emergencia' o 'triple deixis' de la primera persona: yo-aquí-ahora" (23-24). En otras palabras, en la selfie de protesta existe un "signo que representa a su objeto a partir de una conexión física o causal" (Frosh, 2015)4, porque justamente uno de los componentes del mensaje, una parte de lo representado, se emplaza frente al lente de la cámara para ser (auto)fotografiado (Frosh, 2015).

Sin embargo, y siguiendo a Frosh (2015), la selfie de protesta aprovecha la indexicalidad desde el punto de vista de la acción performativa que representa la acción de ejecutarla y publicarla, en lugar de hacerlo desde el referente semántico. En relación a esto último, ¿qué más implica la acción de 'poner el cuerpo'? Pues Parkins (2000) afirma que no es

4 "sign that stands for its object through physical or causal connection." 
posible pensar en agenciamiento político de manera abstracta y que la resistencia política incluye, principalmente, el poner el 'cuerpo material' en acción (2000). Y eso es lo que hacen, entre otras cosas, los autores de las selfies de protesta: ejercen agencia social a través de textos multimodales que ellos mismos producen, comparten y de los cuales son un elemento constituyente.

Al ser el cuerpo del emisor una parte constitutiva de la selfie de protesta, se materializa una "puesta en escena, una presentación del yo en cada representación" (Pérez, 2013). De acuerdo a Pérez (2013) esto corresponde a 'lo visible' o a la 'visibilización', que es parte fundamental de la protesta, permitiendo "la inteligibilidad de los cuerpos como productos del discurso, reconociendo la capacidad del lenguaje de materializarlos y crear zonas visibles de lo considerado invisible u ocultable".

Pisani (2013) señala que la selfie es performativa en tres niveles. El primero de ellos es la preparación del autor del mensaje para la acción, a través del uso de elementos como vestuario, escenario, la posición corporal y gestos presentes en su pose. En segundo lugar, la imagen es, al mismo tiempo, imagen-objeto y performance. Finalmente, el acto de publicar y compartir una selfie en cualquier red social es una extensión de la performance de la imagen-objeto, ya que lleva más lejos el solo acto de capturar el mensaje digital, favoreciendo la posible influencia que la selfie pueda tener sobre otros usuarios de una red social y, en última instancia, sobre aquel o aquellos a quienes se dirige el mensaje.

Se trata de mensajes cuyo contexto de producción y publicación corresponde a protestas sociales. Allí, la selfie se incorpora como otro elemento dentro del conjunto que forma el repertorio de acciones de protesta (Taylor y Van Dyke, 2004; PNUD, 2012). La selfie de protesta es un vehículo de comunicación que contiene demandas o problemáticas sociales que aparecen en ella y que son tan variadas como sus usuarios. Éstos incluyen movimientos estudiantiles, organizaciones feministas y la ciudadanía en general. En suma, la selfie se configura como un mensaje-herramienta de protesta para exigir la justicia social.

Es importante, entonces, comprender la complejidad de la selfie de protesta no solo en su contexto estético, sino también social y político. Además, en palabras de Bajtin (1998) un mensaje "adquiere la plenitud de su sentido únicamente dentro de[I] contexto [donde se ha producido]" (15), porque sólo allí adquiere un significado simbólico. 


\section{Selfie de protesta y semiótica social: Visibilizador de problemáticas y demandas sociales}

En el siguiente apartado revisamos, en la clave de la semiótica social, el contexto desde donde emerge la selfie de protesta. De la misma forma, se intenta explicar cómo los sujetos construyen significados colectivos ante problemáticas también colectivas, utilizando los medios digitales de manera paralela y coordinada con los espacios de manifestación y protesta social offline.

Tal como ha sido anticipado, Bajtin (1998) y Voloshinov (1976) propusieron una semiótica socialmente situada, cuyo objeto de estudio fueron los procesos de producción y reproducción social de sentido comprendidos desde su contexto social. Para ambos autores, los agentes pueden instrumentalizar los códigos, es decir, utilizarlos de manera estratégica para alcanzar determinados fines $y$, además pueden subvertir el sistema establecido. Esto podemos observarlo en las selfies de protesta, al existir una oposición, en el uso, al entendimiento de la selfie y una subversión del espacio tradicional de protesta. Los agentes sociales utilizan otros espacios de significación (Cárdenas, 2014) y "renovadas formas de relación y reflexión [presentes] en la mediación simbólica" (Acosta, 2015), para visibilizar sus demandas y ejecutar sus acciones de protesta en la calle y en las redes sociales de manera simultánea. Dichas acciones se llevan a cabo, además, en espacios donde los derechos de reunión y de libertad de expresión -que configuran el derecho a la protesta social (PNUD, 2012)- no son físicamente reprimidos o, al menos, no directamente. Además, se apropian estratégicamente de medios de comunicación distintos a los medios masivos, cuya propiedad, en el caso de la prensa escrita chilena, es un duopolio (CopesaMercurio). Esto tiene como consecuencia una fuerte estandarización y control sobre los contenidos que se publican y sobre la forma en la que se exponen (Mayorga, del Valle y Nitrihual, 2010).

Además, vemos en la selfie de protesta que el mensaje no es un simple enunciado, sino "un complejo dispositivo que guarda variados códigos, capaz de transformar los mensajes recibidos y de generar nuevos mensajes" (Moulian, 2008: 80). Lo anterior es cierto ya que producir y compartir una selfie de protesta conlleva efectos e interacciones que se producen luego de ser publicados y compartidos estos mensajes en los espacios virtuales, que expanden y complementan los espacios físicos en los que se desarrolla y se mueve una cultura. Entre los efectos e interacciones observados en la etapa inicial de esta investigación, se encuentran selfies incitando e invitando a manifestaciones offline, 
las cuales han desencadenado, a su vez, diálogos online en torno a la temática de las manifestaciones entre los usuarios de las redes. Muchas veces, dichos diálogos incluyen la publicación de nuevas selfies y la demostración de apoyo a determinada causa.

En relación al uso de las tecnologías de la comunicación en contextos contenciosos como la protesta, Millaleo y Velasco (2013) identifican tres niveles: e-movilización, e-movimientos y e-tácticas (17). El primero de ellos corresponde a la utilización de las redes sociales para organizar protestas offline. Mientras tanto, los e-movimientos son aquellos que sólo existen y se desarrollan en Internet. En relación a esto, las selfies de protesta pueden ser mensajes que sólo formen parte de campañas políticas digitales, tal como la campaña digital \#Brelfies, llevada a cabo en Facebook en enero de 2015. El objetivo de esta campaña fue protestar por la no sexualización del amamantamiento, luego que la fotografía de una madre amamantando a su hijo fuera censurada por la misma red social, por ser 'inapropiada'. En respuesta a esto, docenas de mujeres se manifestaron publicando selfies donde aparecen amamantando a sus hijos (Oakley, 2015).

Finalmente, Millaleo y Velasco (2013) distinguen las e-tácticas: estrategias digitales entre las que cuentan campañas a través de e-mail, peticiones online y boicots. Todas ellas "vinculan formas de acción colectiva ya existente con soportes online, y sus capacidades para coordinar e influenciar la sociedad. Estas vinculaciones serán flexibles y pueden integrar en diversos niveles acciones digitales y protestas offline" (18). Un ejemplo de esta dimensión es la campaña \#Bringbackourgirls, organizada para manifestarse frente al secuestro de más de 200 estudiantes en Nigeria en 2014. La iniciativa generó gran movimiento en las redes sociales, incluyendo la producción y publicación de centenares de selfies bajo el hashtag \#Bringbackourgirls, al mismo tiempo que movilizaciones callejeras se levantaban en Nigeria y en otros países (Nagarajan, 2015).

Martín-Barbero (1991) afirma que la cultura es el espacio de expresión de los actores sociales, de confrontación simbólica, de lucha por el sentido y definición de la identidad y, a su vez, son ellos quienes configuran la cultura. En este sentido, hoy, son los actores sociales a lo largo y ancho del planeta quienes están haciendo uso de dispositivos culturales, tales como Internet y las redes sociales, al mismo tiempo que instrumentalizan las modalidades textuales digitales para realizar manifestaciones políticas y confrontaciones simbólicas, tal como en las campañas recién mencionadas. De manera similar, Voloshinov (1976) señala que la 'realidad tecnológica', en un contexto social y cultural determinado, es siempre 
definida por en los usos concretos de los artefactos o dispositivos y, en última instancia, por los eventos sociales mediados tecnológicamente.

Como ha sido afirmado por Walker (2014), "[c]rear y compartir una selfie es un acto de autorepresentación (...) que implica la creación de textos que serán leídos e interpretados" 5 (12) por otros. Esto supone que "una selfie existe en un contexto social, una vez que se ha compartido"6 (Walker, 2014: 12). En este sentido, un rasgo característico de la selfie de protesta es su direccionalidad y el o los objetivos de quien la produce y/o comparte. En palabras de Bajtin (1998), el mensaje "se construye desde el principio tomando en cuenta las posibles reacciones de respuesta para las cuales se construye" (21). Es decir, el autor produce su mensaje esperando la obtención de una reacción o respuesta -por parte de otros usuarios de las redes o directamente de las autoridades interpeladas- posterior a su publicación.

En cuanto a esto último, las selfies de protesta son comúnmente publicadas, compartidas y viralizadas en las redes sociales, entendiendo por viralización la popularización masiva de contenidos "mediante Internet y el compartir a través de páginas web, foros, redes sociales y correo electrónico" (Gómez, Hernández, y Muñoz, 2012: 131). Lo anterior es reflejado por las palabras de Abril (2012), quien ha señalado que "el texto no es sólo un tejido 'interno' de cualidades y acontecimientos semióticos, sino también el momento parcial de un tejido más amplio, espacial, temporal y culturalmente reconocible, o cuando menos inferible". Con esto el autor se refiere a que un texto o mensaje requiere y presupone la existencia de 'redes' o constelaciones textuales, ya que no existen textos aislados. Al contrario, éstos siempre existen en interacción con otros textos (2012). En el caso de las selfies de protesta, son parte de una red de interacciones de mensajes-acciones significantes que ocupan tanto el espacio online como el offline. Por ejemplo, Toret y Monteverde (2014) han llevado a cabo investigaciones vinculadas a las movilizaciones del $15 \mathrm{M}$ en España que describen y demuestran la utilización de las redes sociales online y la calle no como causa-efecto, sino como combinación.

Por otro lado, Abril (2012) afirma que en la selfie "[I]o visual, 'lo que se ve" ", se relaciona estrechamente con lo que no se ve". Las selfies de protesta, por su carácter, tienen un

\footnotetext{
5 "Creating and sharing a selfie is an act of self-representation which a.... means that it involves the creation of texts which will be read and interpreted."

6 "A selfie also exists in a social context, once shared."
} 
efecto visibilizador de problemáticas y demandas sociales en torno a las cuales los usuarios de las redes dialogan. En Chile, un caso emblemático de apropiación de las redes sociales para ejercer agencia política es aquel del movimiento estudiantil. De acuerdo a Cárdenas (2014) "el movimiento estudiantil de postdictadura ha ocupado progresiva y paralelamente tres espacios: las calles, las aulas y las pantallas" (75). El objetivo de la acción colectiva de los estudiantes ha sido exponer públicamente el conflicto social, para conseguir su legitimación social (Cárdenas, 2014), a través de la "comunicación de su lucha política como un núcleo de actuación estratégico, destinado a sobrepasar las limitaciones impuestas por la institucionalidad gubernamental y policial que los constriñe" (75).

En este punto podemos agregar que un acercamiento semiótico a la selfie de protesta podría ser valioso al contribuir a desvelar e identificar qué hacen, particularmente, los emisores y receptores de las selfies de protesta al producirlas, interpretarlas e intercambiar información en torno al contenido y propósito que comportan. Es importante determinar cómo los participantes de interacciones simbólicas mediadas por selfies de protesta construyen los significados individuales y colectivos de las problemáticas a través de estos autorretratos (Abril, 2012). Los individuos se interconectan en las redes sociales y utilizan una forma compartida de protesta, códigos compartidos, a través de los que se autoidentifican y autoorganizan (Revilla, 1996).

Siguiendo a Deleuze y Guattari (1988), se deben considerar los agenciamientos de las selfies de protesta, y la acción performativa individual y social que representan. $Y$ es que las selfies de protesta tienen un significado colectivo, en cuanto son producidas a propósito de demandas colectivas o problemáticas sociales y son utilizadas de manera simultánea por una red de personas unidas bajo la misma causa a través de un lazo virtual o hashtag7, utilizado por los usuarios de las redes sociales para publicar mensajes que se refieren a un mismo tema o causa y participar en un diálogo común. En este sentido, Broullón-Lozano (2015) también ha sostenido que la selfie "constituye un eslabón en una cadena de continuidad narrativa, de manera que solicita la atención y aspira a suscitar un interés de cara a futuras comunicaciones" (225). Esto es lo que podemos observar, por ejemplo, en las interacciones online -valorar, comentar y compartir mensajes- que surgen a partir de una selfie de protesta que ha sido producida y compartida en el marco de una demanda social.

7 Un hashtag es una cadena de caracteres - normalmente palabras- precedidas por el carácter "\#" (Tsur y Rappoport, 2012). 
Tenemos entonces a una multitud de individuos unidos por una causa y enlazados virtualmente a través de un hashtag, pero particularizados al incluir sus rostros en el texto, en lugar de la masa de manifestantes de las protestas callejeras, donde es más fácil ver a un grupo homogéneo en lugar de individuos particulares. Podríamos identificar a esta multitud virtual con el concepto de multitud que han ofrecido Hardt y Negri (2000): una multitud productiva plural; subjetividades globalizadas que han aprendido a navegar en un gran océano y que se encuentran en movimiento constante, formando constelaciones de singularidades y eventos que imponen, a su vez, continuas reconfiguraciones en el sistema (60).

La producción y utilización de selfies de protesta tiene, además, consecuencias offline, tales como denunciar, convocar y exigir. Esto tiene que ver con la siguiente afirmación de Stocchetti y Kukkonen (2011): "desde una perspectiva política, los usos más relevantes que tienen las imágenes son los usos públicos. En ellos, la exhibición de imágenes debería ser entendida como una forma de acción llevada a cabo por un agente para alcanzar un propósito determinado"8 (28). En el caso de las selfies de protesta, su producción obedece a la apropiación e instrumentalización de los códigos. El hecho de compartirlas y generar dinámicas comunicativas a partir de ellas es posible gracias a la interacción social entre los usuarios de las redes digitales y no digitales, y a la existencia de un contexto común de protesta compartido por los productores de estos mensajes (Voloshinov, 1976). En otras palabras, "el centro organizador de toda emisión, de toda experiencia, no está adentro sino afuera, en el medio social que circunda al ser individual" (Voloshinov, 1976: 117).

\section{Semiosis colectiva: El caso de \#Desprotegidas}
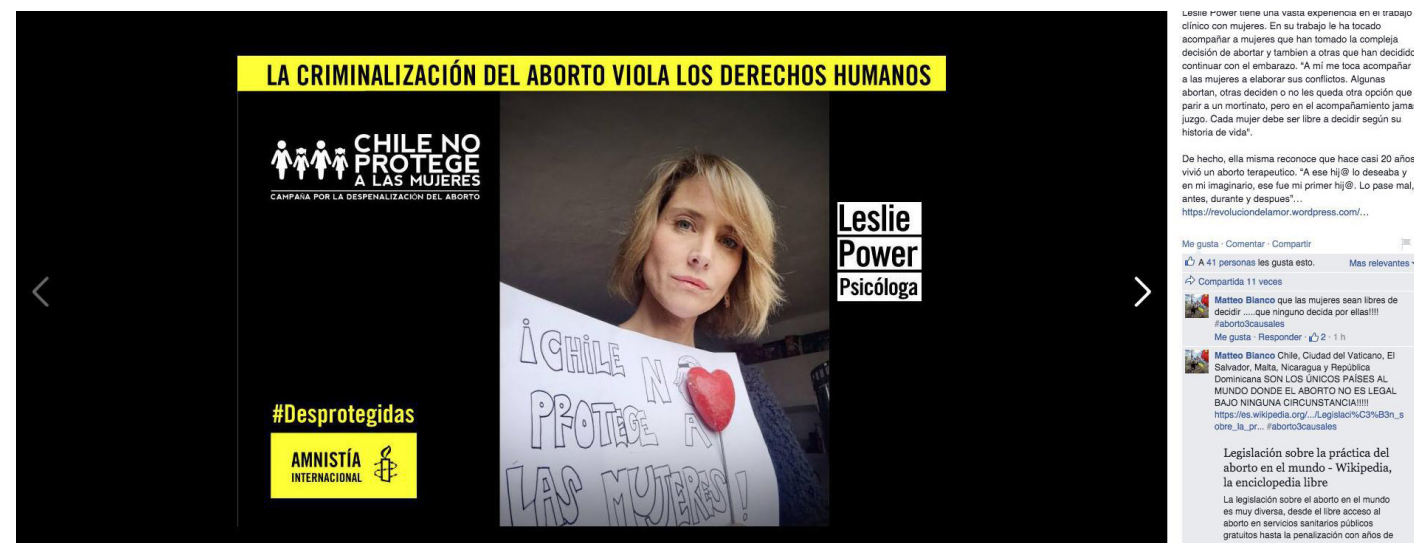

Imagen 3. Afiche digital que incluye Selfie de protesta de la campaña \#Desprotegidas. Fuente: Facebook Aministía Internacional.

8 "[f]rom a political perspective, the relevant uses of images are the public ones. In this use, the display of images should be seen as a form of action performed by an agent in order to achieve a certain purpose." 
En el caso del afiche que contiene una selfie de protesta en Imagen 3, es posible identificar claramente el rostro de la emisora, así como el siguiente enunciado en español: “iChile no protege a las mujeres!". En cuanto al primer elemento, la inclusión del rostro en la selfie es la 'puesta en acción' del cuerpo de la emisora (Parkins, 2000), tal como sucede en una marcha o cualquier manifestación offline. Además, el acto de incluir el rostro, símbolo de identidad por excelencia en el mundo digital (Spencer-Oatey, 2007; Denninger, 2011), individualiza a los agentes sociales en un acto público, tal como el ejercicio individual y secreto de votar en las elecciones en los países democráticos. La fotografía ha sido publicada y compartida bajo el hashtag \#Desprotegidas, el cual se enmarca en la campaña por la despenalización del aborto “iChile no protege a las mujeres!”, lanzada en 2015 por Amnistía Internacional (Al), organización internacional que trabaja por la protección de los derechos humanos. La campaña fue llevada a cabo con el propósito de interpelar a los parlamentarios chilenos para votar a favor de un proyecto de ley presentado por el gobierno de la presidenta Michelle Bachelet, que busca despenalizar el aborto en tres causales específicas. La organización internacional reconoció que a pesar de ser una propuesta con limitaciones, constituía un avance en la protección de los derechos humanos de las mujeres (Colectivo AC Santiago, 2016).

La campaña -que incluyó tanto acciones online (recolección de firmas, producción, publicación y viralización de afiches, videos y selfies de protesta en las redes sociales) como offline (marchas y manifestaciones callejeras)- tuvo un fuerte impacto mediático, logrando cobertura en la prensa latinoamericana y el apoyo de decenas de organizaciones internacionales (Humanas, 2016). Además, la campaña online, que incluía la recolección de firmas, alcanzó finalmente el apoyo de más de 50.000 personas (Colectivo AC Santiago, 2016). La lista de firmas fue entregada a los parlamentarios, siendo el proyecto aprobado por la Cámara de Diputados y encontrándose hoy en trámite en el Senado?.

En este contexto $y$, en particular, en el caso de las selfies de protesta producidas $y$ compartidas en el marco de la campaña mencionada, es posible sostener nuevamente que el acto individual de producir y publicar los mensajes multimodales se transforma en un acto ejecutado en sincronía con otros -online y offline-, llevados a cabo por diversos usuarios unidos por una misma causa en una constelación de singularidades, en palabras de Hardt y Negri (2000). Al mismo tiempo, la práctica compartida de producción de selfies de protesta persigue obtener reacciones-interacciones (Bajtin, 1998) de parte de y entre

9 Campaña del Gobierno de Chile (s.f.) "Todos por Chile. \#YoApoyo3Causales". Recuperado de http://3causales.gob.cl/ 
los usuarios de las redes sociales y de las autoridades, en este caso aquellas responsables por la penalización del aborto en Chile o, desde otro punto de vista, aquellos de quienes depende eliminar el aborto como tipo penal.

De la misma forma, la imagen de la selfie ha sido publicada en una red social particular (Facebook), y varios usuarios han comentado y dialogado en torno a ella. Esta acción nos remite a la idea de semiosis o producción de sentido colectiva, donde se produce una construcción social de significados, enmarcada en un contexto específico, que obedece a una problemática de interés público y político que suscita protesta. Los usuarios: (1) se apropian de un espacio digital, utilizando Facebook como espacio común para organizarse y manifestarse en torno a una demanda colectiva, y (2) utilizan una constelación de códigos compartidos para producir sentido, los que, en el caso de la selfie de protesta en sí misma, conforman un dispositivo digital que condensa varios significados.

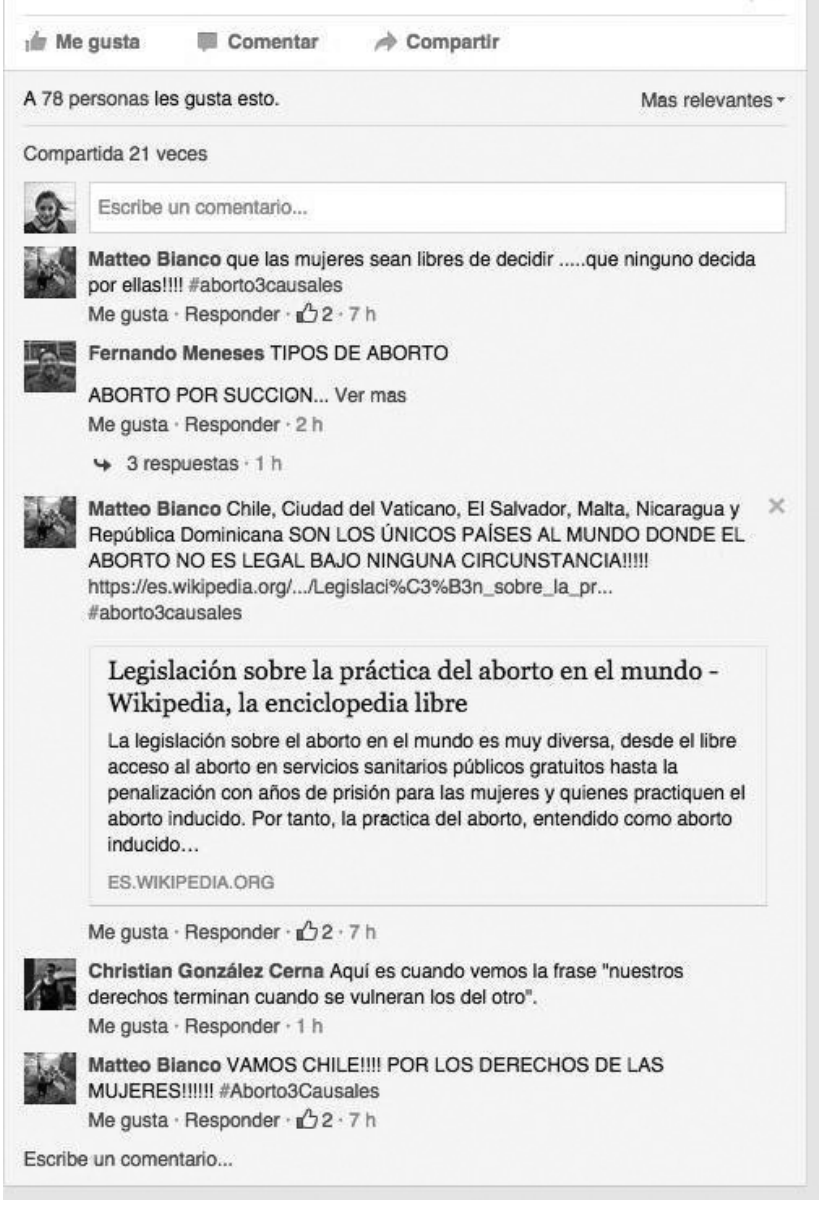

En el caso precedente tenemos un mensaje, un 'enunciado' en palabras de Voloshinov, relacionado de manera concreta con una estrategia política digital basada en una campaña de protesta social. Como ya fue señalado, los agentes sociales no sólo construyen y comparten significados al publicar y compartir ${ }^{10}$ selfies en un contexto común de manifestación o protesta social; también lo hacen al comentar y dialogar en torno a esas dos acciones, como puede apreciarse en Imagen 4.

Imagen 4. Detalle de comentarios a selfie de protesta de la campaña \#Desprotegidas. Fuente: Facebook Aministía Internacional.

10 Al momento de capturar la Imagen 4, la selfie de protesta a la que reaccionan los comentarios había sido compartido 21 veces, tal como se aprecia en la imagen. 
Allí convergen y divergen opiniones en relación a la campaña; algunos usuarios explicitan su apoyo a la causa, mientras otros la cuestionan con mensajes como: "nuestros derechos terminan cuando se vulneran los del otro" (Imagen 4). Además, es posible apreciar que en varios de los comentarios de los usuarios de la red social se hizo uso de la función 'me gusta' (función permitida por la red social Facebook, activada al hacer 'click' sobre el botón llamado de la misma forma) y, finalmente, que algunos comentarios fueron respondidos. Este caso demuestra que la selfie de protesta no existe de manera aislada; por el contrario, es parte de una red de mensajes e intercambios, "está siempre acompañada por actos sociales" (Voloshinov, 1976: 119), actos sociales que llaman a la acción: en este caso la protesta social y las múltiples dimensiones que ella comporta.

\section{Conclusiones}

En este artículo se ha planteado que la enunciación de mensajes políticos de manifestación y protesta en forma de selfie es relevante, en cuanto visibiliza y sociabiliza problemáticas de interés colectivo. Lo anterior es ejecutado por los usuarios de las redes sociales a través de la utilización del formato compartido y que, a la vez, a partir de su publicación ofrece una invitación al diálogo, generándose la producción de respuestas bajo distintos modos digitales (online) y no digitales (offline). En otras palabras, se ha sostenido, siguiendo el enfoque conocido como semiótica social, impulsado por Bajtin y Voloshinov, que al publicarse y compartirse en las redes sociales una selfie de protesta se abre un espacio de interacción simbólica con otros usuarios; una discusión entre la multitud que construye significados colectivos en torno a problemáticas colectivas. Lo anterior es llevado a cabo a partir de la naturaleza performativa y subversiva que comportan estos mensajes multimodales.

Los ejemplos aquí planteados demuestran que la selfie de protesta es un vehículo de comunicación que contiene demandas o problemáticas sociales que aparecen en ella y que son tan variadas como sus usuarios. Como fue mencionado en el artículo, entre estos últimos se incluyen movimientos estudiantiles, organizaciones feministas y la ciudadanía en general. En suma, la selfie se configura como un mensaje-herramienta de protesta para exigir justicia social ya no solo poniendo los cuerpos en acción en las calles sino, además, en la red.

En palabras de Castells (2014), una vez que "los movimientos han alcanzado una masa crítica de impacto social, no desaparecen, aunque no ocupen las plazas y las manifestaciones 
menguen de efectivos". Lo anterior porque son movimientos que "viven siempre en la red, que debaten continuamente, que reflexionan, que denuncian, que se relanzan" (Castells, 2014) con el fin de intervenir públicamente persiguiendo la justicia social.

Finalmente, en cuanto a las limitaciones y futuros aspectos a estudiar en relación a la selfie de protesta, es necesario llevar a cabo una etnografía digital más exhaustiva, acompañada de la aplicación de herramientas tales como entrevistas a los usuarios de las redes sociales que hacen uso de dichos mensajes. Esto para poder profundizar, más allá de la observación y análisis, en la percepción que los propios usuarios tienen de la producción colectiva de sentido generada en contextos de protesta donde mensajes digitales como la selfie son utilizados.

Referencias Abril, G. (2012). "Tres dimensiones del texto y de la cultura visual". IC. Revista científica de información y comunicación, 9, 15-35. Recuperado de https://icjournal.files.wordpress.com/2013/02/1-gonzalo-abril.pdf

Acosta, A. (2015). "Alternancias y disidencias en las redes sociales. ¿Hacia una filosofía de la fotografía?". Ponencia en XI Jornadas de Sociología. Buenos Aires: UBA.

Aguilera, O. (2014). Generaciones: Movimientos juveniles, políticas de la identidad y disputas por la visibilidad en el Chile neoliberal. Buenos Aires: CLACSO.

Bajtin, M. (1998). Estética de la creación verbal. México: Siglo Veintiuno.

Barkai, M. (2012). "Revolution: Share! The role of social media in pro-democratic movements. European Journalistic Centre. Recuperado de http://ejc.net/revolution_share/EJC-RevolutionShareFull.pdf

Broullón-Lozano, M. (2015). "Por una semiótica del selfie en la cultura visual digital”. Revista Científica de Cine y Fotografía, 11, 215-234.

Burns, A. (2015). "Selfie Citizenship: The Political Uses of Personal Social Media Photography". Visual Social Media Lab. Recuperado de https://medium.com/@AnneLBurns/selfie-citizenship-the-politicaluses-of-personal-social-media-photography-8e91bbf71cba

Cárdenas, C. (2014). "Representación de la acción política de los estudiantes chilenos. Movilizaciones de significados en las redes sociales". Última Década, 40, 57-84. Recuperado de http://www.scielo.cl/ pdf/udecada/v22n40/art04.pdf

Colectivo AC Santiago. (2016). "Campaña-Chile No Protege a las Mujeres. Fin a la criminalización del aborto de Amnistía Internacional", (11-03-2016). Recuperado de http://www.acsantiago.cl/index. php/2016/03/11/campana-chile-no-protege-a-las-mujeres-fin-a-la-criminalizacion-del-aborto-deamnistia-internacional/

Deleuze, G. y Guattari, F. (1988). Mil mesetas. Capitalismo y esquizofrenia. Valencia: Pre-Textos. 
Denninger, M. (2011). The interpretation of online identity on Facebook and social networking sites. (Estados Unidos). (Tesis de maestría) Gonzaga University. Faculty in Communication and Leadership Studies. School of Professional Studies, Spokane, Estados Unidos.

Fábrega, J. y P. Paredes. (2013). "La política chilena en 140 caracteres". En Intermedios. Medios de comunicación y democracia en Chile, pp. 199-224. Santiago: Ediciones Universidad Diego Portales.

Farías, G. (2015). "Selfie and the experience of the virtual image". Rupkatha Journal on Interdisciplinary Studies in Humanities, 7 (1), 74-81.

Finol, J. (2014). "Nuevos escenarios en la Corposfera: Fotografía, selfies y neo-narcisismo”. Letra. Imagen. Sonido. Ciudad mediatizada, 11, 111-126.

Frosh, P. (2015). "The gesture image: The selfie, photography theory, and kinesthetic sociability". International Journal of Communication, 9, 1607-1628.

Galindo, J. y González-Acosta, J. (2013). \#YoSoy132: La primera erupción visible. México: Global Talent University Press.

Gómez, R; Hernández, M; y Muñoz, H. (2012). "Comunidades virtuales: la clave para la circulación de contenidos en Internet". En Estructura del mercado audiovisual: resultados, pp. 128-150. Málaga: Grupo de investigación Eumed.net.

Halpern, D. y Valenzuela, S. (2016). "Selfie-ists" or "Narci-selfiers"?: A cross-lagged panel analysis of selfie taking and narcissism". Personality and Individual Differences, 97, 98-101.

Hard, M. y Negri, A. (2000). Empire. Massachusetts: Cambridge University Press.

Humanas. (2016). "Avanza aborto por tres causales". Recuperado de http://www.humanas.cl/ blog/?p=dwecynpru\&paged $=6$

Kress, G. (2005). "Gains and losses: New forms of texts, knowledge, and learning". Computers and Composition, 22, 5-22. doi:10.1016/j.compcom.2004.12.004

Lotman, Y. y Escuela de Tartu. (1979). Semiótica de la cultura. Madrid: Cátedra.

Manghi, D. (2011). "La perspectiva multimodal sobre la comunicación. Desafíos y aportes para la enseñanza en el aula”. Revista diálogos educativos, 11 (22), 4-15.

Martín-Barbero, J. (1991). De los medios a las mediaciones. Comunicación, cultura y hegemonía. Barcelona: Gustavo Gili.

Mayorga, J., del Valle, C., y Nitrihual, L. (2010). "Concentración de la propiedad de los medios de comunicación en Chile. La compleja relación entre oligopolio y democracia". Revista Anagramas, 9 (17), 131-148.

Millaleo, S. y Cárcamo, P. (2013). Medios sociales y acción colectiva en Chile. Santiago: Fundación Democracia y Desarrollo.

Mossberger, K., Tolbert, C. y McNeal, R. (2008). Digital citizenship. The internet, society, and participation. Cambridge: The MIT Press 
Moulian, R. (2008). "Mediaciones rituales y cambio social: Desde nguillatún al culto Pentecostal. Un estudio de casos múltiples y contrastes sobre la transformación de las prácticas rituales en comunidades Huilliche de las comunas de lago Ranco y Río Bueno (Chile)". (Tesis de doctorado). Universidad Complutense de Madrid. Facultad de Ciencias Políticas y Sociología. Dpto. de Sociología IV, Madrid, España.

Nagarajan, Ch. (2015, 14 de abril). “\#Bringbackourgirls hasn't brought back Chibok's girls, but it has changed Nigeria's politics". En The Guardian. Recuperado de http://www.theguardian.com/ commentisfree/2015/apr/14/nigeria-women-activists-boko-haram

Oakley, N. (2015, 29 de enero). "Mums' breastfeeding selfie campaign attracts worldwide support from Mirror Online readers". En Mirror. Recuperado de http://www.mirror.co.uk/lifestyle/family/ mums-breastfeeding-selfie-campaign-attracts-5065977

Oxford Dictionaries. (2015). Selfie. Recuperado de http://www.oxforddictionaries.com/es/definicion/ ingles_americano/selfie

Parkins, W. (2000). "Protesting like a girl: Embodiment, dissent and feminist agency". Feminist Theory, 1(1), 59- 78.

Pérez, L. (2013). "Cuerpos políticos e identidades performativas". XXIX Congreso ALAS 2013. Recuperado de http://actacientifica.servicioit.cl/biblioteca/gt/GT26/GT26_PerezChabaneau.pdf

Pisani, L. (2013). "Performative embodiment and the self(ie): Defining the political feminist selfie". (Tesis de maestría) Laurentian University. Joint graduate program in Communication and Culture, Sudbury, Ontario, Canadá).

PNUD (2012). La protesta social en América Latina. Buenos Aires: Siglo Ventiuno Editores

PNUD (2009). Informe sobre desarrollo humano para Mercosur 2009-2010. Buenos Aires: Libros del Zorzal

Revilla, M. (1996). "El concepto de movimiento social: Acción, identidad y sentido". Última Década, 5, $9-46$.

Sapiezynska, E. (2014). "Los no aparecidos: la protesta social invisible en los grandes medios en Chile y las políticas mediáticas del disenso". Comunicación y Medios, 29, 156-170.

Schuster y Pereyra, (2001), "La protesta social en la Argentina democrática. Balance y perspectivas de una forma de acción política", en Giarraca, N. (ed.), La protesta social en Argentina. Transformaciones económicas y crisis social en el interior del país. Buenos Aires: Editorial Alianza

Senft, T. y Baym, N. (2015). "Selfies Introduction. What Does the Selfie Say? Investigating a Global Phenomenon". International Journal Of Communication, 9 (19), 1588-1606.

Sierra Caballero, F. y Gravante, T. (2016). "Ciudadanía digital y acción colectiva en América Latina. Crítica de la mediación y apropiación social por los nuevos movimientos sociales". La Trama de la Comunicación, 20 (1), 163-175.

Spencer-Oatey, H. (2007). "Theories of identity and the analysis of face". Journal of Pragmatics, 39 (4), 639-656. 
Stochetti, M. y Kukkonen, K. (2011). Images in use. Towards the critical analysis of visual Communications. Amsterdam/Philadelphia: John Benjamins Publishing Company

Taylor, V. y Van Dyke, N. (2004). "Get up, Stand up": Tactical Repertoires of Social Movements". En Snow, D., Soule, S. y Kriesi, H. (eds.), The blackwell companion to social movements, pp. 294-310. Oxford: Blackwell Publishing Ltd.

Toret, J., y Monterde, A. (2014). "15-M: acontecimiento, emociones colectivas y movimientos en red". Vanguardia, 50, 36-43.

Vázquez, M. (2003). "Bases para una teoría del emplazamiento". En Teoría del emplazamiento: Aplicaciones e implicaciones, pp. 21-34. Sevilla: Ediciones ALFAR.

Voloshinov, V. (1976). El signo ideológico y la filosofía del lenguaje. Buenos Aires: Ediciones Nueva Visión Walker, J. (2014). "Seeing ourselves through technology. How we use selfies, blogs and wearable devices to see and shape ourselves". New York: Palgrave McMillan. semiótica social”. Comunicación y Medios, 25 (33), 35 - 53. 